1980s to be a crucial component of Nazi high-performance medicine.

Ohler pays more attention to the perpetrators of Nazi drug experiments than to their victims. He cites experiments with mescaline, trying to create a 'truth' drug, from the perspective of the Dachau doctor Kurt Plötner, for instance. My book Victims and Survivors of Nazi Human Experiments (Bloomsbury, 2014) draws on original findings from more than 15,000 prisoners' narratives of coerced medical testing - including of mescaline - at Auschwitz and Dachau, but is not referenced. Nor does Ohler mention the victims of another notorious experiment. Seven British Royal Navy commandos endured experimentation with stimulants, including cocaine and amphetamines, at the Sachsenhausen concentration camp. After a forced, three-day march carrying heavy loads, five were executed in 1945. Ohler mentions only a German survivor.

But my key issue is with Ohler's central claim that Pervitin and Eukodal induced a sense of invincibility, first enhancing operational boldness, then destroying the Nazis' ability to engage with military collapse. He also concludes that addiction to ever-stronger doses of patent medicines clouded Hitler's judgement on strategic issues concerning Dunkirk and Crimea. He reduces every twist and turn of the war on the German side to addiction. Yet the US and UK military used amphetamines as part of a highly successful scientific and technological war effort without apparent issues with addiction.

Ohler ends at what he dubs the "Last Exit Bunker", with Hitler addicted to Eukodal. That title encapsulates my problem with Blitzed. It strings the reader along with facile phrases such as "High Hitler" and "One Reich, One Dealer", calling the bunker-bound Führer a "superjunkie". This is a text full of short cuts and speculation rather than a balanced synthesis of a mass of literature and sources to date, rendered readable and accessible..

Paul Weindling is research professor in the history of medicine at Oxford Brookes University, UK.

e-mail:pjweindling@brookes.ac.uk

\title{
CYBERNETICS
}

\section{A mathematician of mind}

\author{
Manuel Blum examines a biography of cybernetics \\ pioneer Warren McCulloch and his revolutionary times.
}

$\int$ n n 1958, in my junior year at the Massachusetts Institute of Technology, Richard Schoenwald - whose tutorial on Sigmund Freud I was taking - encouraged me to meet the anti-Freud, Warren McCulloch. Where Freud had written The Future of an Illusion (1927), a critique of religion, McCulloch countered with The Past of a Delusion (1953), a reference to Freud (the title says it all). I dropped into McCulloch's basement lab and found myself facing a tall, striking character: long beard, coarse Scottish wool suit, books piled to the ceiling. I confided that I wanted to understand how the brain works. He handed me a sheaf of his 'Research Laboratory of Electronics' publications. These showed how to construct neural networks of formal (model) neurons that could control for errors in those neurons. Weeks later, I stated and proved a theorem that his formal neurons could be configured to do what his networks needed. With that, I was in, mentored and inspired by McCulloch for the next six years and counting.

In Rebel Genius, science historian Tara Abraham offers a biography of McCulloch (1898-1969) that shines a light on the twentieth-century revolution in the mind sciences and cybernetics - the scientific study of automatic control in animals (including humans) and machines.

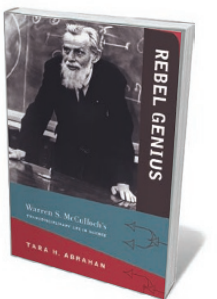

Rebel Genius:

Warren S.

McCulloch's

Transdisciplinary

Life in Science

TARA ABRAHAM

MIT Press: 2016.

McCulloch insisted that the 'magic' of the brain lay in what electrical networks can do (nowadays, chemistry would count for more). He asserted that the magic would arise whether the networks were constructed from neurons, which he called software (later, meatware) or vacuum tubes, which he called hardware.

Like mathematician and computer scientist John von Neumann, $\mathrm{McCulloch}$ was interested in errors. Neurons, like vacuum tubes, were unreliable. The problem, he pointed out, was that neuronal thresholds, which affect what neurons compute, are constantly changing. "Thresholds fall when we drink coffee. They rise when we drink alcohol. Yet we can still talk; we can still walk." At least, he could. Computers were then, as now, designed to work with components that make virtually no errors. But at that time, a computer could run for only minutes before errors crept in. How the brain manages with

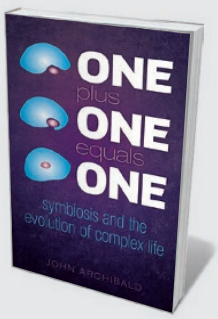

One Plus One Equals One John Archibald (Oxford Univ. Press, 2016) Exuberantly describing the greening of Earth 500 million years ago, John Archibald vivifies the origins of complex life. His microbiologist predecessors star, including Carl Woese, who first sequenced rRNA to track evolution (see Nancy Moran's review: Nature 510, 338-339; 2014).

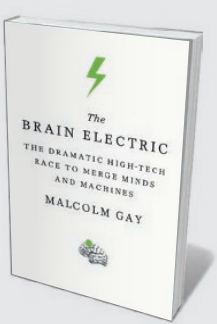

The Brain Electric

Malcolm Gay (Farrar, Straus and Giroux, 2016) People enduring amputations, once subject to messy surgery, are now at the forefront of neuroprosthetics research. Malcolm Gay explains the science behind an evolving technology that binds brain impulse to exoskeletons, enabling people with paralysis to move. 
$>$ faulty neurons was a big question. (And as transistors drop to the size of atoms, errors again become a serious problem in computing.)

McCulloch held sway in a phenomenal period for many fields of science. His multitude of friends and colleagues included neuroscientist Jerry Lettvin, who would drop by to demonstrate one of Hermann von Helmholtz's extraordinary experiments on the eye. Artificialintelligence pioneer Marvin Minsky showed McCulloch how to construct Venn diagrams of any number of variables (to represent neurons with many inputs). And Manuel Cerrillo convinced McCulloch that he was a genius at filter-design with a self-built hi-fi set that could separate musical instruments from the human voice in a recording.

McCulloch bubbled with ideas. In one co-written paper, 'A Logical Calculus of Ideas Immanent in Nervous Activity' (W. S. McCulloch and W. Pitts Bull. Math. Biophys. 5, 115-133; 1943), he argued that neurons must be capable of inhibition as well as excitation. If not, they would compute only a very small class of 'monotonic' functions. McCulloch told me that neurophysiologists of his time rejected this idea because inhibition had never been observed. His prediction - that inhibition exists in the brain - was later proved experimentally.

Abraham appraises the McCulloch I knew knowledgeably, accurately and insightfully. For example, she writes: "McCulloch's scientific life at its heart was less a philosophical project and much more about transcending disciplines, the power of science to do away with metaphysics, and the power of a neurophysiological, biological psychiatry to eliminate dualist accounts of the mind and non-biological practices in psychiatry." This is both perceptive and accurate.

There are also many aspects of McCulloch in Abraham's book that I did not know, a lot that I wanted to know and got, and a lot that I did not even know I wanted to know. For example, Abraham's account of psychologist

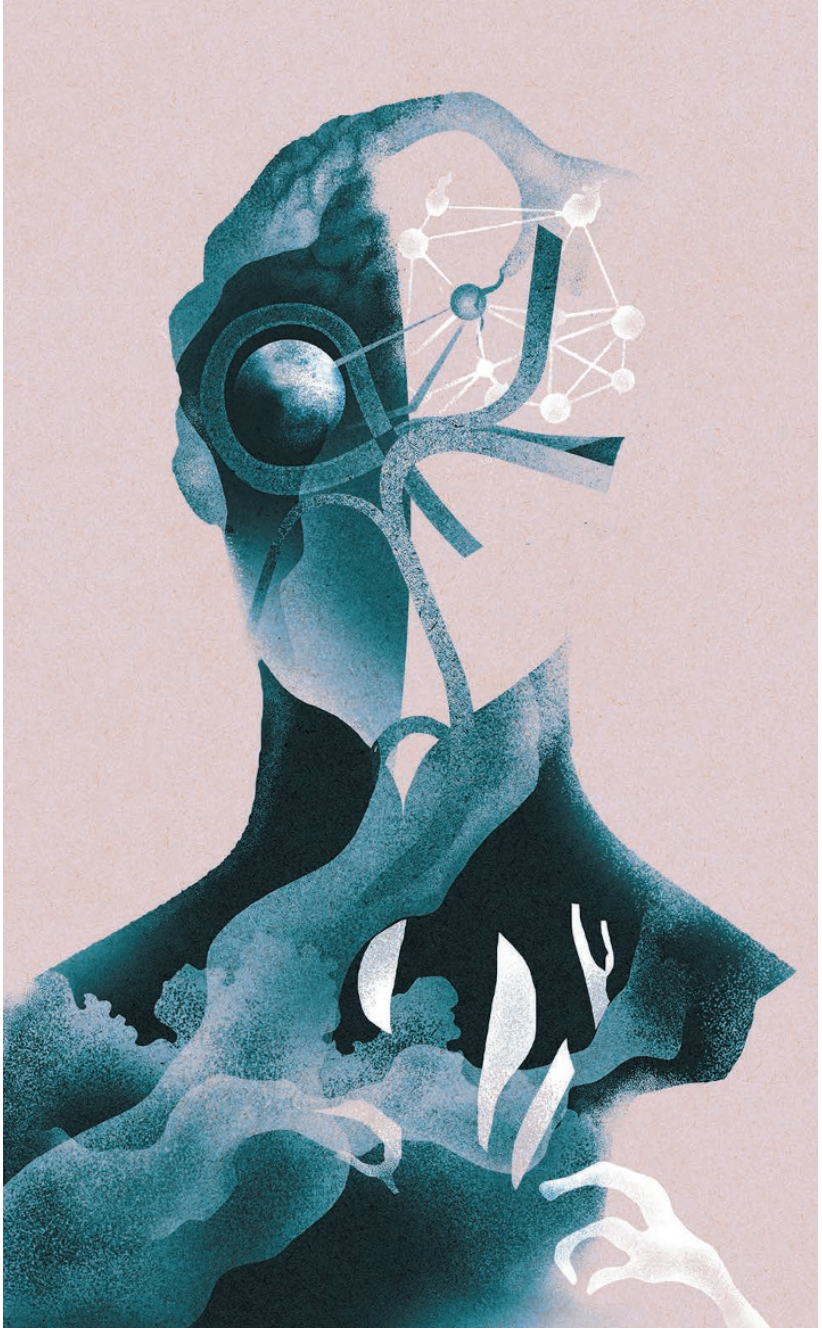

version of the event is accurate, but misses the soul of it. What I recall McCulloch saying is that the president of Haverford, Quaker philosopher Rufus Jones, asked, "Warren, what wilt thee be?" to which McCulloch answered, "I don't know." "What wilt thee do?" "I don't know. But," McCulloch added, "I do have a question: 'What is a number that a man may know it, and a man that he may know a number?"' To which Jones rolled back his head and roared, "Thee wilt be busy for the rest of thy life!"

Not everything about McCulloch comes up roses, and Abraham is critical of certain aspects of his approach. She quotes neurophysiologist Ralph Gerard's critique on the Macy conferences on cybernetics - where McCulloch aimed to get psychologists, neurophysiologists, mathematicians and engineers talking. Gerard's words were very much a critique of McCulloch himself. He noted how the group began "in the 'as if' spirit. Everyone was delighted to express any idea that came into his mind, whether it seemed silly or certain or merely a stimulating guess that would affect someone else... Then, rather sharply it seemed to me, we began to talk in an 'is' idiom. We were saying much the same things, but now saying them as if they were so."

McCulloch was a polymath: a Clark Hull reveals Hull to be another enormously interesting individual - a proponent of behaviourism who worked in motivation and learning, and who thought that the problem of mind is solvable through scientific theory.

What Abraham does not capture enough of, for my taste, is the striking impression that McCulloch made on his audience intellectually, through his astute observations, and visually, through his erudite Scottish bearing. Abraham describes a formative experience of McCulloch's: when he was "a student at Haverford College in Pennsylvania in 1917, a teacher asked him what he planned to do with his life". Her neurophysiologist who was also a physician, psychiatrist, poet, writer, architect, engineer and mathematician. His was the all-encompassing intellect that could and did bring these disparate fields together both in the Macy meetings and in his lab. Through its discussions of McCulloch in the round, Rebel Genius is an excellent portrait of the man and his time, and a significant contribution to the history of science.

Manuel Blum is the Bruce Nelson University Professor of Computer Science at Carnegie Mellon University in Pittsburgh, Pennsylvania.

e-mail:mblum@cs.cmu.edu

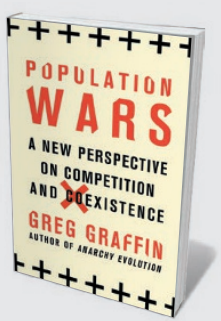

Population Wars: A New Perspective on Competition and Coexistence Greg Graffin (Thomas Dunne, 2016) Zoologist, geologist and punk rocker Greg Graffin explores how an "us vs them" attitude has infiltrated human consciousness and driven populations to war, despite our unique power to plan our future by reflecting on the past.

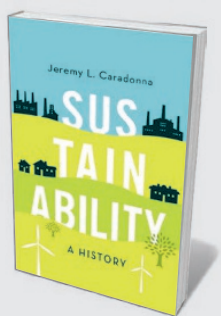

Sustainability: A History

Jeremy L. Caradonna (Oxford Univ. Press, 2016) Historian Jeremy Caradonna chronicles the arc of sustainability from its roots in eighteenthcentury European forestry to contemporary local food and zero-waste movements, and its emphasis on balance and the long view over economic growth. Emily Banham 